\title{
O ROMANCE SOB APERTO: AS PERSONAGENS E OS EXCURSOS NARRATIVOS EM CASAS PARDAS, DE MARIA VELHO DA COSTA
}

Rui Miguel Mesquita ${ }^{1}$

RESUMO: O romance modernista reduzira drasticamente a construção espacial e social da personagem. A ficção de Maria Velho da Costa, pelo contrário, procurou reagir a essa constrição através da exploração de novas formas de construção de identidade narrativa e de descrição espacial. Por esse motivo, são especialmente importantes os excursos espalhados ao longo do romance Casas Pardas.

PALAVRAS-CHAVE: Narratologia; Construção da Personagem; Descrição Espacial.

\section{THE NOVEL UNDER DURESS: CHARACTERS AND NARRATIVE EXCURSUSES IN MARIA VELHO DA COSTA'S CASAS PARDAS}

ABSTRACT: The modernist novel had drastically reduced the spatial and social construction of characters. Maria Velho da Costa's fiction, however, tried to react to that constriction through the exploration of new forms of construction of narrative identity and spatial description. The excursuses scattered throughout Casas Pardas are, for this reason, particularly important.

KEYWORDS: Narratology; Character Building; Spatial Description.

\footnotetext{
${ }^{1}$ Investigador do Instituto de Literatura Comparada Margarida Losa (Universidade do Porto). Bolseiro de Pós-Doutoramento da Fundação para a Ciência e a Tecnologia (REF. SFRH / BPD / 63039 / 2009).
} 


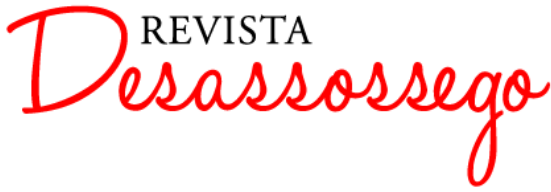

O interesse da narratologia pelos processos de inserção das personagens num espaço físico, comunicacional ou social é manifesto. Esta preocupação é uma constante da disciplina, desde os seus primórdios; se recuarmos a um dos seus momentos inaugurais, o número especial da revista Communications publicado em 1966, verificaremos que o conhecido artigo de Roland Barthes, "Introduction à l'analyse structurale des récits", dedica uma das suas seções precisamente ao problema da personagem. No entanto, o fato de ele ser subsumido dentro da temática da "ação" indica por si que este tema está longe de ser consensual. Há, com efeito, uma tendência na narratologia estrutural (ou "clássica"), bastante influenciada pelo apuramento formal do romance modernista, para que a centralidade da ideia de personagem, herdada do romance realista (e associada a uma noção pré-crítica da própria subjetividade) fosse repudiada; nesse sentido, não surpreende que a narratologia clássica entenda a personagem sobretudo em termos funcionais, ao jeito de Vladimir Propp. Todavia, a evolução da disciplina gerou uma acepção mais generosa do conceito de personagem; a narratologia "pós-clássica" caracteriza-se por, entre outros sinais distintivos, entender a personagem como elemento integrante ou mesmo criadora de universos narrativos. Exemplo dessa evolução é a teorização de David Herman à volta deste tema: apesar de não ser possível o regresso à noção oitocentista de personagem, o tema ocupa um lugar de destaque na sua proposta metodológica; a personagem deve ser entendida como um participante de pleno direito no universo narrativo (HERMAN, 2004, p. 115). É uma evolução que acompanha a reação, no romance pós-modernista, ao rigor extremo e à obsessão epistemológica do romance modernista.

O romance de Maria Velho da Costa é já bastante devedor desta reação. Ela passa primariamente pela afirmação lúdica das virtualidades da construção espacial de que o romance modernista se ocupara; mas, sem que tal constitua um regresso do romance realista, há também a vontade de reconstruir a importância da referência, da noção de que a linguagem vive de uma relação com uma presença física. Em suma, de uma vontade de atenção ao mundo, de uma generosidade primordial que aceita as dificuldades do registro dessas experiências sensoriais. Apesar da impossibilidade de uma sua plena adequação e da sua exigência, as possibilidades de demonstração da linguagem são suficientemente tentadoras para que esta não se encerre no rigor modernista. Como medita Elisa, a romancista latente de Casas Pardas: 
Sei muito bem que era preciso um acto de força para reunir isto tudo. Ou duma tão perfeita atenção que Eu pudesse ser como um espelho passável, as criaturas punham-se-me nos olhos e Eu deixava-as passar através para um mundo onde tudo estava passando-se aceitando e Eu só tinha que o estar assim, sentada num banco da Avenida, desta, desta terra, a sorver o mundo todo pelos olhos para o lado de cá do de lá (COSTA, 1996, p. 76).

Podemos por isso falar de uma substância narrativa que, nesses termos, é o objeto de uma estratégia dupla, através da qual o autor procura compreender o mundo que lhe é dado e transfigurar, por via desse esforço de compreensão, esse próprio mundo. É importante salientar que essa compreensão é incompatível com a ideia mais estreita de seleção (daí referirmos uma generosidade autoral). Não negando uma certa preocupação arquitetônica (ela mesmo um elemento natural da construção espacial), o romance pode ser a promessa de um imprevisível e informe momento de realização no próprio "lugar".

Casas Pardas está estruturado primariamente em volta de quatro sequências triádicas de "casas", cada uma delas atribuída a uma das três figuras principais do romance (Elisa, Mary e Elvira), sendo que, a separar rigorosamente esses trios, há uma "terça casa", capítulo fulcral e como que uma mise en abyme teatral (aliás, dividida em três atos) do próprio romance. Ou seja, na sua relação completa, I Casa de Elisa: Vaga; I Casa de Elvira: Epifania; I Casa de Mary: Acquosa; II Casa de Elisa: Os Trabalhos de Casa: Pote Podre; II Casa de Elvira: Lacrimosa; II Casa de Mary: Gávea; A Terça Casa; IV Casa de Elisa: Angelus; IV Casa de Elvira: Stella; IV Casa de Mary: Cápsula; V Casa de Elisa: Língua; V Casa de Mary: Declinação; V Casa de Elvira: Atrium.

Poderíamos mesmo dizer que uma das linhas primárias de estruturação desse romance é a evolução ocorrida entre a primeira e a última das casas, "Vaga" e "Atrium"; onde no início há um espaço por ocupar, no final haverá o prenúncio de um espaço à beira da sua plena realização, a presença de um tempo novo que prometa resolver as contradições internas do primeiro espaço. Temos assim de considerar um jogo de correspondências não só no interior dessas sequências, como também entre as próprias sequências; há desse modo um efeito progressivo na estruturação do romance através do qual cada "casa" se converte numa unidade de montagem passível de ser combinada em modos menos lineares.

A sucessão das diferentes "casas" é acompanhada de uma transformação no uso dos pronomes pessoais, como que significando o poder de vinculação existencial da 
linguagem. Aliás, a questão dos pronomes pessoais é, em Casas Pardas, de especial importância para esse efeito progressivo. $\mathrm{Na}$ verdade, os pronomes pessoais assumem nesse romance um volume afetivo que impele a dinâmica narrativa; Elisa, entre outras observações, anota a propósito: "a minha pátria são os pronomes dolorosamente pessoais" (COSTA, 1996, p. 384). Como refere Manuel Gusmão, no prefácio que escreveu para o mesmo romance,

Gestos polares da polifonia intersubjetiva, os pronomes pessoais organizam (...) a distribuição das casas nas sequências do livro, e é a alteração da relação entre o nome da personagem e a pessoa pronominal, na qual é dita, que constitui a grande operação, que na última sequência fecha, em movimento, a construção das personagens (apud COSTA, 1996, p. 26-7).

Assim, na última sequência, Elisa, anteriormente referida como Eu, passa a ser descrita na terceira pessoa; Elvira assume a primeira pessoa, depois de ser abundantemente invocada como $\mathbf{T u}$; Mary, por sua vez, depois de ocupar ao longo do romance o espaço da terceira pessoa, é tratada, a partir da sua catástrofe fatal na "quarta casa", por Tu. Essas transformações acompanham a própria evolução afetiva e psicológica das três personagens, como se toda essa evolução fosse dependente de uma totalidade interpessoal que excede qualquer uma das partes. Por conseguinte, a evolução das personagens é parte integrante e imprescindível de uma transformação coletiva.

A centralidade dos pronomes ilustra, por outro lado, a própria instabilidade dos nomes próprios. As personagens são apresentadas ao leitor como uma cifra, um semnúmero de combinações possíveis a partir da estruturação interna e externa do romance. Da mesma forma que as personagens se confrontam em permanência com a sua própria opacidade, assim o leitor é forçado a assumir uma leitura indeterminável, que reconheça as incertezas da sua própria criação. É impossível uma poiesis estritamente pessoal, nos moldes em que o romance oitocentista frequentemente entendeu essa construção de si; há um desencontro entre a existência individual e as suas possibilidades narrativas que apenas pode ser diminuído por um contrato coletivo de narração.

Nesses termos, essa externalidade deve ser avaliada pela tensão que motiva entre as diferentes personagens e a sua evolução. Aliás, essa tensão é particularmente relevante em Casas Pardas, pois há diferenças sensíveis na forma como cada uma das três protagonistas a absorve no seu projeto narrativo. Por outro lado, essa volubilidade separa Casas Pardas do romance realista, no qual as mudanças de estado das personagens assumem 
necessariamente consequências drásticas sobre todos os outros elementos do romance. Aqui, pelo contrário, há toda uma dimensão lúdica de montagem que impede o caráter necessário da intriga romanesca; dir-se-ia que o mito dá finalmente lugar a uma dimensão plenamente histórica. É uma dimensão lúdica que não esconde certa estranheza do sujeito face a si mesmo, a qual assume uma dimensão social - na medida em que o trabalho mitológico, aqui fundador de uma comunidade, é perturbado pela erosão (diríamos que "parda") das concepções de personalidade que lhe servem de base. Por outras palavras: onde antes mito e personagem se implicavam reciprocamente, deve haver agora uma emancipação das personagens e uma exploração lúdica (por oposição ao rigor modernista) dos efeitos dessa emancipação sobre o universo narrativo - até sobre a própria comunicação literária e a inserção do romance na sua própria realidade social.

Há duas personagens principais que se definem em movimento, Elisa e Elvira. Não deve surpreender que a primeira "casa" de Elisa esteja "vaga"; com efeito, a sua evolução ao longo do romance vai no sentido de ocupar um espaço que seja seu, não aquele que a organização social lhe destinou. Significativamente, Elisa é a personagem cujo nome conhece contínuas variações (Elisa, Maria Elisa, Zizi, Elisinha, Zizinha, Ziza ou mesmo Beliza e Elisadédala). É a personagem que deseja escrever o seu destino, encontrar a sua "língua" (título da sua última "casa") natural. Dir-se-ia mesmo que Casas Pardas é também o Künstlerroman de Elisa, na medida em que detalha os sucessivos passos que a personagem vai tomar de forma a assumir a sua vocação de escritora, representada pela assunção da terceira pessoa; é uma personagem em rutura com os confinamentos sociais e linguísticos. A circunstância de Elisa ser a personagem que incorpora por excelência a dimensão coletiva do romance far-nos-ia crer que, em última análise, a sua perspetiva assume no final um lugar como que matricial no próprio romance; no entanto, tal crença neutralizaria aquela que é uma dimensão fundamental de Elisa, o seu processo de aprendizagem, no qual a eventualidade de uma "sabedoria" comunal é, mais do que o momento primário, um objetivo ou uma etapa final. Como também adverte Manuel Gusmão:

o facto de Elisa andar a aprender para escritora favorece a ilusão: Casas Pardas seria o livro que Elisa escreveu depois de ter chegado ao que chegou na sua última casa, o livro em que Elisa conta como chegou a poder escrevê-lo. (...) Porém, os exibidos modos da construção narrativa, a passagem da $1^{a}$ à $3^{a}$ pessoa em relação a Elisa, mostram que não é bem assim. Mostram que Elisa, Mary e Elvira são todas elas personagens de um livro cujo sujeito emerge da construção de todas elas (apud COSTA, 1996, p. 33). 
Diríamos que Elisa é a personagem mais expansiva do romance, aquela que tem como tarefa tecer uma rede narrativa e estilística que suporte o efeito progressivo que configura o romance. Em causa está a necessidade de afastar a "roupa velha" que impede uma expansão não só individual, mas também coletiva; uma revitalização daquela linguagem que, ao contrário da sua definição enquanto "consciência real prática, que, existindo para os outros homens, existe para mim próprio pela primeira vez" (COSTA, 1996, 399-400), se diminui persistente e insidiosamente a si própria (e a quem nela participa). A procura de uma linguagem renovada confunde-se com o próprio questionamento dos mitos fundacionais que suportam as narrativas diminuidoras. É a permanência no tempo desses mitos fundacionais que permite a uma estruturação ilegítima da realidade manter o seu sistema de parcelamento pessoal, ou seja, é a vigência desses mitos para além do seu momento próprio que, por fim, perturba a própria naturalidade do devir histórico. Elisa é a personagem que procura a identificação com o seu momento, encontrar o instante preciso no qual seja possível afirmar a sua rotura com as "casas pardas" que impedem o fluxo natural da sociedade.

Elvira, por seu lado, é indício dessas "casas pardas" e um exemplo entre vários de certa tendência "populista" na ficção de Maria Velho da Costa, em contraste com a habitual descrição sólida de ambientes da média burguesia. Mais do que expansiva como Elisa, Elvira é uma personagem em transformação: o percurso de Elvira é o da conquista do seu próprio nome, a saída da "estranheza" em que se encontra atolado o seu ponto de origem. Perdida de início num universo ancilar sobre o qual incide um lastro histórico que lhe retira a participação na dialógica comunitária, a tarefa de Elvira não pode ser outra que não a sua plena admissão nessa dialógica, e aí se legitima a sua assunção final da primeira pessoa, como que uma vontade indelegável de afirmar a sua identidade (pessoal, de classe, de gênero...), "a cara da aurora lavada na nascente" (COSTA, 1996, p. 441). A energia primordial libertada por essa vontade é enfim uma promessa de plenitude e de uma generosidade afetiva que permite gerir as aspirações globais de Elvira (e, por arrastamento, aliviar o lastro histórico do qual ela é o indício mais forte); daí a nota de arrebatamento com que termina o romance (e tão contrastante com o seu tom angustioso), "Quem me dá tempo de falar da abundância de paz que irradio de meu poder doar-me ao que gozo, ao que espero, ao que peno? (...) Mas durmo já, a língua inerme, porém no merecimento da felicidade entendida que só da felicidade pode vir" (COSTA, 1996, p. 442). 
Esse arrebatamento é assim o culminar do processo de transformação a que Elvira se entrega; o afeto que movimenta a sua inteira identidade, num sentido como que deleuziano do conceito: "L'affect est la décharge rapide de l'émotion, la riposte, alors que le sentiment est une émotion toujours déplacée, retardée, résistante. Les affects sont des projectiles autant que les armes, tandis que les sentiments sont introceptifs comme les outils" (DELEUZE/GUATTARI, 1998, p. 497-8). Sem qualquer cedência sentimental, Elvira é por fim a demonstração da própria futilidade da noção de nome, na medida em que a sua assunção da primeira pessoa é também a recusa de a conceber em termos meramente individuais. É possível afinal que a nomeação seja o último reduto do parcelamento pessoal que confere um caráter pardacento ao devir das personagens (mais pardacento para Elvira do que para qualquer outra personagem). A nomeaşão seria nesses termos um obstáculo final à plena responsabilização afetiva, uma instância opaca das personagens que constitui o seu lastro mais incômodo e difícil e, por fim, o antagonista da potencialidade lúdica da demonstração na própria construção linguística. Enquanto Elisa procura reconverter incessantemente o seu nome até a um ponto em que configure uma constelação de tal modo densa que impeça qualquer (re)apropriação diminuidora, Elvira visa objetivamente a elisão do nome (ou, pelo menos, do seu caráter determinante).

Mary, por sua vez, é a personagem que fica; não é uma personagem em movimento, é ela própria a vítima de uma deslocação afetiva que a encerra no lugar que lhe foi destinado. Na verdade, Mary/Maria das Dores/Mimi assume de forma tão completa a função de vítima que não conhece uma projeção ontogênica. É, nesses termos, uma personagem que, sem sentido, regride; como é referido num seu sonho inicial,

Sabe, sem saber onde está, que é nessa direção que tem que ir, mas não vai para nada. Vai. (...) Mary começa a decrescer, a decrescer e tem tempo de se pôr um avental de folhos bordado em abertos, de casa e pensar, Sou como a Alice mas não tenho cogumelo para comer (COSTA, 1996, p. 107).

Perpetuamente deslocada, Mary incorpora uma irresponsabilidade incorrigível que (não) se assume nos diversos momentos narrativos em que participa, um retardamento (latecoming) que marca a sua própria temporalidade dentro do romance.

Mary/Maria das Dores é, em suma, a personagem sentimental do romance e o grande contraponto de Elvira, cuja projeção sobre o devir não conseguiria compreender. Confinada numa difícil relação com a família de "filha menor", dificuldade à qual se acrescenta a futilidade do seu próprio casamento com Frederico, o luxo constritivo da sua 
existência quotidiana tem como última saída o suicídio; isolada da dialógica comunitária em que se movimentam Elisa e Elvira, o epitáfio de Mary dificilmente poderia ser mais acutilante:

desde criança que há entre ti e o que te circunda uma venda, uma fossa de grande silêncio e cegueira eriçada de objetos, de gente desviada, e agora puseram-se todos a falar e a mover ao mesmo tempo, nesgas de frases, feições claríssimas, arestas residuais de gestos e tempos onde nunca espiaste, onde desviaste a vista soterrada no susto (COSTA, 1996, p. 370).

Mary é de tal forma marcada pela proliferação de objetos à sua volta (o que atinge o seu auge na "Terça Casa") que neles mais convictamente se reconhece do que nos seus próprios gestos ou ações. Preenchida inutilmente por esses objetos, o suicídio é assim o único ato de força de Mary, muito distante da generosidade afetiva de Elvira ou da expansão criadora de Elisa. Uma boa parte da evolução sofrida por Elisa e Elvira é a aprendizagem de uma perspetiva que possa ser de verdade um princípio de orientação ou a gestação de um mundo, as "casas" de Mary são, em contrapartida, um exercício de desmontagem do espaço alternadamente construído por Elisa e Elvira. Para esse efeito, Mary terá de ser a personagem que é reprimida pelo seu próprio espaço, a tal ponto que se torna impossível evitar uma inércia debilitante. Essa inércia, em última análise, só pode resultar na destruição da própria personagem; personagem sem perspetiva e incapaz de impor um ritmo próprio às suas ações, esse parece ser o único sentido que Mary encontra para a sua existência.

A oposição entre a criação de um universo narrativo por parte de Elisa e Elvira e a sua "não-criação" por parte de Mary atinge o seu clímax na seção central do romance, "Terça Casa". A "Terça Casa", como que uma peça de teatro embutida dentro do romance, constitui uma longa exploração das possibilidades de criação de universos narrativos próprios (ou até incompatíveis, no que se distancia substancialmente do romance oitocentista). Do mesmo modo que, nessa "Terça Casa", as três protagonistas se reúnem no mesmo lugar pela primeira vez, há também uma justaposição abrupta de espaços, já mencionados de forma dispersa no romance, que será um fio condutor ao longo de todo o capítulo. Aliás, facilmente datável dos anos da dita "primavera marcelista" e com o fim do regime em pano de fundo, o tempo histórico no qual decorre o capítulo favorece esta integração e sublinha o ambiente excecional que o caracteriza. Nas palavras de Manuel Gusmão, "a própria concentração relativa do espaço de tempo em que a ação se dá acentua 
esse carácter de tempo de crise, entretanto vivido como que ao "ralenti", aparentemente suspenso de algo que se vai passar, de algo que espera, se busca, se sofre" (apud COSTA, 1996, p. 42). Há de fato uma dissonância crescente entre o que "acontece" e aquilo que "poderá vir", a qual é uma marca característica desse capítulo. O efeito combinado da compressão temporal e de uma série de insólitas integrações espaciais, marcas da natureza lúdica de Casas Pardas, confere à "Terça Casa” a sua natureza de ponto crítico do romance, de demonstração de uma divergência fundamental entre diferentes percepções do tempo e do espaço que é exacerbada pela excecionalidade da situação histórica.

O cenário proposto no primeiro ato é como que uma fantasmagoria eletrodoméstica. "Uma ampla cozinha iluminada muito bem a fortes flocos de luz fluorescente" (COSTA, 1996, p. 241) (lembrando os cenários de Jacques Tati, em Playtime, ou os descritos por Georges Perec em Les choses), ou seja, um espaço determinado pela desmesura: “...grandes placards de madeira...”, “...imensas máquinas de lavar roupa...”, “...imenso fogão de ferro...", “...grandes tachos de cobre...”, desmesura de tal modo indiferente às pessoas que nele circulam que "o encenador é livre para, por exemplo, não manter a escala dos objetos à dimensão das pessoas". O aspeto dessa cozinha moderna, "O mais possível bonita", em boa parte prenuncia o desenrolar deste "Primeiro Acto", muito determinado pelos contrastes insólitos cuja acumulação é afinal a sua matéria essencial.

O acumular de tensões é interrompido, ainda no "Primeiro Ato", pelo súbito "Recitativo de Lídia", um primeiro momento de promessa como que messiânica; de recuperação dos "atos do ócio próprios à prometida real" (COSTA, 1996, p. 250). Denúncia de um declínio "discreto" da burguesia ou apelo à revolta dos oprimidos, o "recitativo" é seguramente o prenúncio de um poder revolucionário que supere duradouramente as incongruências da sociedade vigente; trata-se, enfim, de uma substituição das "dinastias" que impeça um afastamento definitivo entre os seres humanos. Advirta-se, no entanto, que o "Recitativo" não é um momento final de superação de todas as contradições visadas anteriormente; com efeito, ele próprio está bloqueado nas suas pretensões. É um momento de irrealidade tão irrecuperável como a existência decididamente frívola dos convivas.

Essa espiral de irrealidade culmina no trecho que encerra o primeiro ato, "A Dama das Neves", como que uma alegoria da vacuidade e da privação emocional que tal ordenamento social determina; lembremos que este trecho descreve a "penada solidão" de 
um "grande demónio que vivia no mais alto pico da mais alta serrania da terra toda" (COSTA, 1996, p. 254). O próprio ambiente doméstico dessa criatura não deixa de funcionar, na sua opulência e desmesura, como um derivado do cenário geral deste primeiro ato,

dentro do castelo que estava todo aparelhado de bons madeiros arruçados e panos de fina lã com traça de batidas a gamos e javardos, com céus de anil e prados da papoila e da bonina mais subtil, havia dispostas por todos os cómodos fornalhas ardentes de cobre e oiro fino, lares sempre acesos todo o dia toda a noite (COSTA, 1996, p. 254).

Por seu lado, a menina prometida que surge em resposta às preces do grande demônio evoca afinal "os filhos dos meus filhos" anunciados anteriormente por Lídia. Embora a sua erupção contagie a própria Mary, repetidamente descrita como a vítima preferencial, é uma erupção cujo significado apenas revela tudo aquilo que não existe nesse jantar. Diríamos mesmo: revela os desejos frustrados de Mary e dos seus amigos, desejos cujo espectro vai assumindo contornos cada vez mais ominosos à medida que a "Terça Casa" chega ao seu término.

Esaa acumulação ininterrupta irá culminar no tremor de terra que constitui peripécia maior deste "drama dentro do romance". O tremor de terra final é tão devedor do terremoto histórico de Fevereiro de 1969 como do tempo histórico convulso em que acontece. Diríamos que, onde não acontece uma rotura temporal consequente, tem de aparecer uma rotura espacial que compense essa falta; ou, como Elisa por fim lamenta, "isto volta sempre ao mesmo por mais que a terra trema” (COSTA, 1996, p. 286). Subsequente à "Oração de Sapiência” proferida por Elvira, autêntica demonstração de um saber natural do qual os convivas estão alheados, o tremor de terra tem o dom de revelar as diferenças de preparação entre as personagens face à pressão do inadiável (ou insubstituível). Assim, não surpreende que Elvira aparente ser a personagem mais segura de si: "Sara segura a travessa do pato e benze-se com a outra mão. Elvira permanece com a mão de aviso no ar. Não parecem demasiado assustadas”. Caracteristicamente, Mary é a personagem que aparece como que emparedada pelo espaço circundante: "as mulheres aos gritos, exceto Mary que vacila procurando o apoio das paredes e mesas. Os homens dão manifestas provas de descontrole. (...) Berram todos quase ao mesmo tempo" (COSTA, 1996, p. 282). 


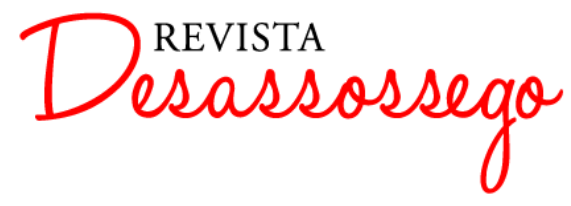

De qualquer modo, o tremor de terra vale como a deflagração final de uma integração narrativa de sucessivos espaços opostos, a qual não deixa de assumir um aspeto marcado de crítica social. É justo salientar, a esse propósito, o exemplo impávido dos avós de Elisa e Mary, pois, como refere a própria Elisa, "a terra deles não tremia” (COSTA, 1996, p. 286). A referida diferença fundamental entre percepção temporal e percepção espacial não seria tão manifesta se ela não fosse vivida num momento crítico, em que a experiência do tempo e do espaço é submetida a diversas distorções. Por oposição ao saber natural de Elvira (e, adivinhamos, dos avós de Elisa), há um descontrole vivencial no grupo de personagens à volta de Elisa e Mary que se converte no próprio estado de expectativas para longe do qual tanto Elisa como Elvira se movem (esse objetivo é o espaço da própria futuridade). Esse descontrole tem, aliás, efeitos discursivos evidentes, como demonstrado pelos múltiplos excursos dispersos ao longo do romance, os quais funcionam não só como mecanismos certos de rotura espacial, mas também como indícios excecionais de caracterização das personagens a eles associadas e do seu espaço social. Exemplos desses excursos são, na "Terça Casa", os diferentes "recitativos de Lídia", sucessivas variações à volta da sua condição de empregada doméstica e da sordidez muitas vezes inerente a essa condição; uma sordidez para a qual o único remédio parece ser a união de Elisa e de Elvira, consubstanciada na sentença, "não peças a quem pediu nem sirvas a quem serviu" (COSTA, 1996, p. 251).

O "Segundo Acto" constituíra de resto um exercício contínuo de encontros inusitados, em rigor instáveis. Desde logo, o contraste entre o esplendor dos interiores e a sugestão claustrofóbica de um espaço fechado: "uma casa de jantar sumptuosa tão fechada quanto a cena possa permiti-lo. Nenhuma presença de janelas ou sugestão de luz exterior" (COSTA, 1996, p. 257). Indício da instabilidade primária desse cenário é o fato de que "o lustre treme com grande fragor cada vez que é pronunciada a palavra poder" (COSTA, 1996, p. 257). Em qualquer caso, trata-se de sublinhar o alheamento completo deste grupo face ao seu meio, incapaz de encetar um gesto de aproximação aos seus envolventes sem garantir previamente um esplendor que, em rigor, não é mais do que um postiço civilizacional. Nesse sentido, o seu espaço "natural” é tão estereotipado quanto aleatório, uma vez que não lhe assiste maior "naturalidade" do que esse esplendor e a sua realização momentânea. A própria descrição das personagens é reveladora de como elas são definidas, 
antes de tudo, pelos seus acessórios. As diversas referências culturais aqui presentes são em boa parte uma extensão prestigiada desses acessórios.

"Em boa parte", no entanto, porque Elisa denuncia esse mesmo deslocamento; é a personagem que assiste em esforço, "que se senta muito mal à mesa, apoiando-se uma bochecha no cotovelo até à deformidade da cara que não sorriu nunca, perna cruzada em T e pé agarrado, sugerindo incómodo debaixo da bota" (COSTA, 1996, p. 258). A sua vontade de chocar (“esta pequena está a exceder-se”; COSTA, 1996, p. 264) é também a vontade de superar a artificialidade constrangedora do evento, uma falta de coesão espacial (e, por arrastamento, vivencial) que, de fato, só um choque frontal e completo poderia compensar. Pela sua própria natureza de personagem em movimento, Elisa pode afrontar de igual para igual os discursos concorrentes de Frederico e dos seus amigos e, com os seus apartes, desmontar a preciosa maquinação retórica com que eles procuram legitimar uma situação que não pode ser mais do que provisória. Aliás, os seus repetidos apartes destacam-se dos diálogos que os envolvem e constroem um espaço mais imediato de comunicação com o leitor. A construção teatral da "Terça Casa" é, em parte, justificada por essa necessidade de valorizar os apartes de Elisa, os quais criam não só novas situações narrativas, mas também um efeito de estranhamento face ao discurso das outras personagens. Em suma, criam um espaço alternativo em relação ao dos outros convivas e participam de outros momentos de integração narrativa em que são reunidos os diversos elementos em confronto no romance.

A criação de espaços alternativos não depende só da intervenção de personagens como Elisa; o romance é pontuado por pequenos textos que se destacam do corpo principal de Casas Pardas, habitualmente através da intercalação de um título sugestivo, e que, em geral, constituem uma explicação realçada daquilo que os precede. Assim acontece com os dois primeiros destes excursos, na "primeira casa" de Elvira, a "Epifania do teu Menino" (COSTA, 1996, p. 93) e o "Monólogo da Vaqueiro", alusão jocosa à marca de margarinas (COSTA, 1996, p. 98). Se, no caso da "Epifania", temos uma alegoria da gravidez e parto de Elvira, ou mesmo da própria ideia de futuridade que o seu percurso desvenda, o "Monólogo", exercício fulgurante de integração conceptual que mostra como afinal as margarinas não estão tão longe de Gil Vicente e do nascimento do teatro português, constitui uma enumeração risível da substituição de sucessivas marcas de rusticidade por novos adereços, sinais de "urbanidade" que, no entanto, não aparentam 
reunir em volta de si um valor substancialmente diferente daquela rusticidade agora repudiada. Contudo, "é preciso saber. Tudo tem um princípio, Elvirazinha" (COSTA, 1996, p. 99). A sordidez da sua vida de empregada doméstica não é pelo menos incompatível com a promessa de um outro futuro para Elvira, de uma outra situação narrativa que não a atual, aliás representada pela repetição anaforizante da expressão "pode dizer-se que a casa é grande...". Grande, diríamos, ao ponto de abrigar, no meio do aviltamento, as aspirações de Elvira, ou, como se observa no final dessa casa, "há pássaros grandes por cima das cidades" (COSTA, 1996, p. 104).

O mesmo não acontece na casa seguinte, a de Mary, onde os excursos não terão tanto essa função de criação de espaços alternativos como a de proceder à sua invalidação. É significativo que, por contraponto à contemplação quase extática do horizonte por Elvira no final da sua casa, a casa de Mary seja encerrada com uma série de instruções de maquilhagem; outro exemplo desses excursos narrativos, com a diferença de que, no caso, há uma tabulação radical do espaço, preenchido aqui por uma série de procedimentos anônimos e estandardizados. Essa tabulação já havia, aliás, sido encetada por um excurso anterior, "Persona" (COSTA, 1996, p. 121-2), o qual, como que uma paródia dos planos fixos bergmanianos, congela a perspetiva sobre o rosto de Mary, sobre a sua "cruenta opacidade" e o quanto revela da sua frustração vivencial. Trata-se, em todo o caso, de uma ferramenta pela qual é efetuado um tratamento especial da dinâmica narrativa: ao integrar vertiginosamente diversos espaços diegéticos ou ao retardar um deles em particular, ao focar um zoom ou ao abrir uma perspetiva panorâmica sobre o horizonte espacial, o excurso tem, em Casas Pardas, o efeito de enfatizar certos aspetos fulcrais da narrativa que, num discurso narrativo mais neutro, não guardariam esse caráter fulcral. Ou seja, não será exagerado dizer que, por via desses excursos, a gravidez de Elvira, o rosto de Mary, as suas roupas, se convertem em espaços fundamentais do romance.

Seja pela criação de espaços alternativos, seja pela sua tabulação, os excursos narrativos ao longo de Casas Pardas constituem assim uma importante ferramenta de manipulação do universo narrativo. Se bem que o espaço físico de Casas Pardas seja facilmente discernível, correspondendo à Lisboa dos tempos finais do Estado Novo, não é menos verdade que, por mais determinado que seja, o mesmo espaço físico pode ser motivo de perspetivas divergentes (e os excursos são uma estratégia privilegiada de demonstração disso mesmo). Não surpreende assim que o próprio espaço mental que é 
gerado por esse romance seja influenciado sobremaneira pelos diferentes recursos de montagem aqui usados pela autora. Os excursos narrativos são um desses recursos, e é inegável o seu efeito em termos de gestão das expectativas que o leitor tece em volta das personagens e dos lugares. Os excursos parecem funcionar assim como um lugar de investigação das origens de cada interveniente, de revelação dessas dimensões que, num discurso mais linear, permaneceriam ocultas.

Podemos dizer, em conclusão, que os excursos são, em Casas Pardas, a última consequência do modo particular como Maria Velho da Costa entende as diferentes personagens. Não sendo possível voltar à confiança oitocentista na possibilidade de representação plena da personalidade e da sociedade, os excursos são a marca mais visível da divergência de pontos de vista que essa perda de confiança implica. São, ao mesmo tempo, uma demarcação clara dos processos modernistas: onde, no romance modernista, havia uma quebra dos nexos de causalidade narrativa, há aqui, pelo contrário, uma proliferação incontrolável desses nexos (levada aliás ao extremo nos romances subsequentes, Lucialima e Missa in Albis). Ou seja: mais do que a radical dúvida modernista sobre a possibilidade de representação da interação entre a personagem e o seu universo (a tal ponto que, como diria a narratologia clássica, ela se converte numa "função"), a personagem é aqui o ponto a partir do qual é possível (ou não, no caso de Mary) engendrar uma multiplicidade narrativa capaz de emprestar um sentido à existência pessoal e coletiva. Sem a certeza realista de que o romance pode representar a realidade, é certo; mas é precisamente essa "incerteza" que permite assumir sem reservas a liberdade criadora que constitui o valor exemplar de Casas Pardas.

\section{REFERÊNCIAS BIBLIOGRÁFICAS}

BAL, Mieke. Narratology: Introduction to the Theory of Narrative. Toronto: University of Toronto Press, 1997.

COSTA, Maria Velho da. Casas Pardas. Lisboa: D. Quixote, 1996 [1977].

DELEUZE, Gilles e GUATTARI, Félix. Mille Plateaux: Capitalisme et Schizophrénie 2. Paris: Minuit, 1998 [1980].

FLUDERNIK, Monika. Towards a 'Natural' Narratology. London: Routledge, 1996. 
GUSMÃO, Manuel. Uma Raz̃ão Dialógica: Ensaios sobre Literatura, a sua Experiência do Humano e a sua História. Lisboa: Avante, 2011.

HERMAN, David. Story Logic: Problems and Possibilities of Narrative. Lincoln: University of Nebraska Press, 2004 [2002].

HUTTO, Daniel. Folk Psychological Narratives: The Sociocultural Basis of Understanding Reasons. Cambridge: MIT, 2008.

RYAN, Marie-Laure. Possible Worlds, Artificial Intelligence and Narrative Theory. Bloomington: Indiana UP, 1991.

Artigo recebido em 01 de maio de 2014

Artigo aceito em 15 de junho de 2014 